\title{
A BIOGEOGRAPHIC APPROACH TO ESTMATING PALEOLONGITUDE OF SUSPECT TERRANES IN TECTONIC RECONSTRUCTIONS OF THE PACIFIC REGION
}

BELASKY, Paul, Department of Earth and Space Sciences, University of California, Los Angeles, California 90024-1567, U.S.A.

Suspect terranes in western North America and northeastern Siberia contain Permian taxa which were endemic to the Tethyan region. According to one hypothesis, the rocks containing these faunas were transported across the Paleopacific Ocean by plate motion during the Mesozoic. An alternative explanation is that the Tethyan species crossed the Paleopacific Ocean in much the same way as modern Indo-Pacific corals migrated into central America. A third hypothesis attributes their presence in North America to dispersal through a marine corridor between the Tethys and Paleopacific oceans. Trend-surface analysis of modern and Permian biogeographic data is a new approach to understanding the origin of these exotic faunas and constraining the paleolongitude of the circum-Pacific terranes which contain them. The eastward decline in generic diversity of Recent Indo-Pacific corals and larger foraminifera across the Pacific Ocean may be used as a model for the distribution of their respective ecological and biogeographical analogs, namely, Permian Tethyan rugose corals and fusulinids in the Paleopacific Ocean.

In order to test the method, data on the generic diversity of modern corals were compiled from 137 areas in the Indian and Pacific Oceans. A second-order polynomial surface was constructed from the biogeographical data. It is nearly symmetrical about the Equator, and the average pole to its plane of symmetry is located $\leq 1^{\circ}$ away from the pole of the Earth's axis of rotation. It is closer to the actual pole than are mean virtual magnetic poles obtained from Quaternary lavas at three well-sampled islands: Hawaii, Tahiti and Easter Island. Trend-surface analysis of the biogeographic data on larger foraminifera yields similar results. Thus the estimate of the position of the Earth's pole of rotation using biogeography rivals that obtained from the best available palaeomagnetic data.

The same kinds of data may also be used to place longitudinal constraints on paleogeographic reconstructions. The gradual decline in diversity of corals eastward across the Pacific Ocean may be used to find the location of an island if its paleomagnetically-derived latitude and the value of coral diversity are both known. In order to test this approach, the values for coral diversity at Hawaii, Tahiti, and Easter Island were removed from the data, and a second-order polynomial surface was obtained from the reduced data set. The islands were then returned to the map using their paleomagnetically-derived latitudes and the longitudes obtained from the contour lines of the diversity surface. Easter Island, Hawaii and Tahiti were placed approximately $600 \mathrm{~km}$ northeast, $3,700 \mathrm{~km}$ southeast and $600 \mathrm{~km}$ southeast of their actual sites, respectively. These distances are small compared with the total width of the Pacific and Indian oceans $(26,000 \mathrm{~km})$. Evidence that latitudinal and longitudinal gradients in faunal diversity existed during the Permian provides the rationale for the application of the proposed method to fossil data of that age. 